\title{
Utilization of drug in patients admitted with abnormal uterine bleeding in a tertiary care teaching hospital
}

\author{
Dhivya Govindasamy ${ }^{1 *}$, Padmavathi Karunakaran', Rajalakshmi Ramesh ${ }^{1}$, \\ Kamalavarshini Paramasivamsasanger ${ }^{1}$, Rajalakshmi Ponnusamy ${ }^{2}$
}

\author{
${ }^{1}$ Department of Pharmacy, Annamalai University, Annamalai Nagar, Tamil Nadu, India \\ ${ }^{2}$ Department of Obstetrics and Gynecology, RMMCH, Annamalai University, Annamalai Nagar, Tamil Nadu, India
}

Received: 24 May 2020

Revised: 03 July 2020

Accepted: 08 July 2020

\section{*Correspondence:}

Dr. Dhivya Govindasamy,

Email: dhivyagovindasamy4@gmail.com

Copyright: (c) the author(s), publisher and licensee Medip Academy. This is an open-access article distributed under the terms of the Creative Commons Attribution Non-Commercial License, which permits unrestricted non-commercial use, distribution, and reproduction in any medium, provided the original work is properly cited.

\begin{abstract}
Background: The objective of the study was assessing utilization of drug in patients admitted with Abnormal Uterine Bleeding in a tertiary care teaching hospital.

Methods: The observational study was conducted at Department of Obstetrics and Gynecology, Rajah Muthiah Medical College and Hospital, Annamalai University, Annamalai Nagar, Tamil Nadu, from the period of July 2019 to September 2019. A total 30 gynecology patients were included.

Results: A total 30 patients most of the patients were between the age groups of 36-45 years 66.6\%. The most common clinical condition AUB and co-morbidities condition were 19 (63.3\%). The majority of patient were prescribed with ferrous sulfate 27 (90\%). The defined daily dose (DDD) per patient for norethisterone 36 followed by ferrous sulfate 23.11. The average number of drugs per prescription 10.8, percentage of drug prescribed in generic name $69.56 \%$ and number of drugs prescribed from NLEM-2015 86.95\%, number of drugs prescribed from EDL2019 were $69.56 \%$ and percentage of prescription with antibiotic $80 \%$, percentage of prescription with injection $70 \%$. Conclusions: This study has shown the utilization of drugs prescribed in AUB patient. The most commonly prescribed drug was ferrous sulfate and most prescribed antifibrinolytic drug was tranexamic acid for treating AUB.
\end{abstract}

Keywords: DDD, AUB, Drug utilization, Anti-fibrinolytic drugs

\section{INTRODUCTION}

Menstrual disorders are the most common gynecologic conditions in the general population. Abnormal uterine bleeding (AUB) mean both heavy and irregular menstrual bleeding, and many patients experience the combination of these symptoms. The substantial impact of abnormal uterine bleeding (AUB) lies not only in its prevalence, but its effect on quality of life, associated loss of productivity, and major health care costs. ${ }^{1}$ AUB is regarded as a sign of possible uterine disease, including acute and chronic AUB. It is the most common symptom and main complaint among Chinese women of childbearing age in the gynecological clinic, accounting for $30 \%$ of gynecological outpatient clinics. ${ }^{2}$

Palm-Coein is a useful acronym provided by the International Federation of Obstetrics and Gynecology (FIGO) to classify the underlying etiologies of abnormal uterine bleeding. The first portion, Palm, describes structural issues. The second portion, COEI, describes non-structural issues. The $\mathrm{N}$ stands for "not otherwise classified. $\mathrm{P}$ for polyp, A for adenomyosis, $\mathrm{L}$ for leiomyoma, $\mathrm{M}$ for malignancy and hyperplasia $\mathrm{C}$ for coagulopathy, $\mathrm{O}$ for ovulatory dysfunction, $\mathrm{E}$ for 
endometrial disorders, I for iatrogenic and $\mathrm{N}$ for not otherwise classified. ${ }^{3}$

One or more of the problems listed above can contribute to a patient's abnormal uterine bleeding. Some structural entities, such as endocervical polyps, endometrial polyps, or leiomyomas, may be asymptomatic and not the primary cause of a patient's AUB. ${ }^{3}$ Drug utilization research can increase our understanding of how drugs are being used. It can be used to estimate the numbers of patients exposed to specified drugs within a given time period. Such estimates may either refer to all drug users, regardless of when they started to use the drug (prevalence), or focus on patients who started to use the drug within the selected period (incidence). ${ }^{4}$

It can describe the extent of use at a certain moment and/or in a certain area (e.g. in a country, region, community or hospital). Such descriptions are most meaningful when they form part of a continuous evaluation system, i.e. when the patterns are followed over time and trends in drug use can be discerned. Researchers can estimate (e.g. on the basis of epidemiological data on a disease) to what extent drugs are properly used, overused or underused. It can be used to compare the observed patterns of drug use for the treatment of a certain disease with current recommendations or guidelines. ${ }^{4}$

The ATC classification system divides the drugs into different groups according to the organ or system on which they act and according to their chemical, pharmacological and therapeutic properties. The DDD is the assumed average maintenance dose per day for a drug used for its main indication in adults. It should be emphasized that the DDD is a unit of measurement and does not necessarily correspond to the recommended or prescribed daily dose (PDD). Doses for individual patients and patient groups will often differ from the DDD as they must be based on individual characteristics (e.g. age and weight) and pharmacokinetic considerations. ${ }^{4}$ Drug utilization figures should ideally be presented as numbers of DDDs per 1000 inhabitants per day or, when drug use by inpatients is considered, as DDDs per 100 bed-days or when calculating epidemiology diseases, DDD/patient indicator is often used and it expresses the treatment intensity/total exposure according to a defined study period. ${ }^{4}$ If the actual dose used is equivalent to the DDD, the DDD/patient would also express the number of treatment days in a specific period. ${ }^{5}$ And AUB is a varying condition in regularity, frequency, duration of flow and amount of blood loss depending upon the patient. ${ }^{6}$ Hence this study was carried out by using DDD per patient indicator.

\section{METHODS}

The observational study was conducted at Department of Obstetrics and Gynecology, Rajah Muthiah Medical
College and Hospital, Annamalai University, Annamalai Nagar, Tamil Nadu, from the period of July 2019 to September 2019.

\section{Inclusion criteria}

Inclusion criteria were patient who were admitted in obstetrics and gynecology department, diagnosed with abnormal uterine bleeding and with other co-morbid conditions during the study period.

\section{Exclusion criteria}

Exclusion criteria were patient who are not willing to participate and not providing informed consent form, patient was pregnant, lactating and unconscious.

\section{Study procedure}

Involves the collection of all relevant data from cases (demographic details, drugs, principle diagnosis and comorbid conditions) obtained from gynecology department.

\section{Study method}

Prescribed drugs were classified and analysed WHO prescribing indicators average number of drugs per prescription, percentage of drug prescribed in generic name, number of drugs prescribed from NLEM (2015), number of drugs prescribed from EDL (2019). ${ }^{7-9}$ Percentage of prescription with anti-biotic and percentage of prescriptions with injection where compared with WHO standards.

Drugs were classified using anatomical and therapeutic classification (ATC) system (WHO-ATC 2020), and consumption of drugs measured by defined daily dose (DDD) per patient.

\section{DDD/patient}

This indicator is often calculated in pharmacoepidemiological databases and expresses the treatment intensity/total exposure according to a defined study period. If the actual dose used is equivalent to the DDD, the DDD/patient would also express the number of treatment days in a specific period. ${ }^{5}$

$\mathrm{DDD} /$ patient $=$ Utilization in DDDs/Number of patients

Utilization in DDD $=$ No of items issued $\times$ amount of drug per item/WHO DDD

\section{Statistical analysis}

Data was entered and analyzed with microsoft excel 2007. Descriptive statistics were used to analyze the 
results. Percentage and averages of the variable were also calculated to compare the data with other findings.

\section{RESULTS}

Total of 30 patients were divided into three age trends 25 35 years $13.3 \%, 36-45$ years $66.6 \%$, and $46-55$ years $20 \%$. In our study most of the patients come under 36-45 years $66.6 \%$ were given (Table 1 ).

Table 1: Age wise distribution of patients.

\begin{tabular}{|l|l|l|}
\hline Age in years & No. of patients & $\%$ \\
\hline $\mathbf{2 5 - 3 5}$ & 4 & 13.3 \\
\hline $\mathbf{3 6}-\mathbf{4 5}$ & 20 & 66.6 \\
\hline $\mathbf{4 6 - 5 5}$ & 6 & 20 \\
\hline
\end{tabular}

Out of 30 patients 7 (23.3\%) were diagnosed with AUB. Co-morbidities were calculated. Patients with two comorbidities 19 (63.3\%) and the condition were AUB with severe anemia, fibroid uterus, diabetes mellitus, simple hyperplasia, III-degree UV prolapsed with cystocele. And the patients with three co-morbidities $4(13.3 \%)$ and the conditions were AUB with systemic hypertension with diabetes mellitus, hypothyroidism with severe anemia, hypothyroidism with diabetes mellitus were shown in (Table 2).

Table 2: Distribution of co morbidities in patients.

\begin{tabular}{|l|l|l|}
\hline No. of diseases & No. of patients & $\%$ \\
\hline $\mathbf{1}$ & 7 & 23.3 \\
\hline $\mathbf{2}$ & 19 & 63.3 \\
\hline $\mathbf{3}$ & 4 & 13.3 \\
\hline
\end{tabular}

Among 30 prescription, the majority of the patient were prescribed with ferrous sulfate $27(90 \%)$ followed by mebendazole $25(83.3 \%)$, calcium carbonate $24(80 \%)$ and glibenclamide, orinidazole, mefenamic acid, pantoprazole, b complex were prescribed 2 (6.66\%) each and least prescribed drugs were amoxicillin, bisacodyl, erythromycin were 1 (3.33\%) each. Anti-fibrinolytic therapy for AUB patients, out of 30 patients were prescribed tranexamic acid $12(40 \%)$ and mefenamic acid $2(6.66 \%)$ further information was shown in (Table 3$)$.

WHO prescribing indicators like average number of drugs per prescription 10.8, percentage of drug prescribed in generic name $69.56 \%$ and number of drugs prescribed from NLEM-2015 86.95\%, number of drugs prescribed from EDL-2019 were $69.56 \%$ and percentage of prescription with antibiotic $80 \%$, percentage of prescription with injection $70 \%$ were shown in (Table 4).

In our study, prescribed drugs were calculated in terms of DDD per patient for norethisterone (G03AC01) (36 DDD/patient) followed by ferrous sulfate (B03AA07)
(23.11 DDD/patient) and the least is bisacodyl (A06AB02) (1 DDD/patient) and followed by calcium carbonate (A12AA04) (0.64 DDD/patient). The ATC code and the DDD per patient of the prescribed drugs were shown in (Table 5).

Table 3: Drugs prescribed in AUB patients.

\begin{tabular}{|lll|}
\hline Drug name & No. of patients & $\%$ \\
\hline Ferrous sulfate & 27 & 90 \\
\hline Mebendazole & 25 & 83.3 \\
\hline Calcium carbonate & 24 & 80 \\
\hline Doxycycline & 19 & 63.3 \\
\hline Metronidazole & 19 & 63.3 \\
\hline Ranitidine & 17 & 56.6 \\
\hline Vitamin C (ascorbic & 14 & 46.6 \\
acid) & 12 & 40 \\
\hline Tranexamic acid & 5 & 16.66 \\
\hline Paracetamol & 5 & 16.66 \\
\hline Levothyroxine & 4 & 13.3 \\
\hline Amlodipine & 3 & 10 \\
\hline Tramadol & 3 & 10 \\
\hline Norethisterone & 3 & 10 \\
\hline Metformin & 3 & 10 \\
\hline Cefixime & 2 & 6.66 \\
\hline Glibenclamide & 2 & 6.66 \\
\hline Ornidazole & 2 & 6.66 \\
\hline Mefenamic acid & 2 & 6.66 \\
\hline Pantoprazole & 2 & 6.66 \\
\hline B complex & 1 & 3.33 \\
\hline Amoxicillin & 1 & 3.33 \\
\hline Bisacodyl & 1 & 3.33 \\
\hline Erythromycin & \\
\hline
\end{tabular}

Table 4: WHO prescribing indicators.

\begin{tabular}{|lll|}
\hline Prescribing indicator & $\begin{array}{l}\text { Values } \\
\text { obtained } \\
(\%)\end{array}$ & $\begin{array}{l}\text { WHO } \\
\text { standards } \\
(\%)\end{array}$ \\
\hline $\begin{array}{l}\text { Average number of drugs } \\
\text { per prescription }\end{array}$ & 10.8 & $1.6-4.8$ \\
\hline $\begin{array}{l}\text { Percentage of drug } \\
\text { prescribed in generic }\end{array}$ & 69.56 & 100 \\
\hline $\begin{array}{l}\text { Number of drugs } \\
\text { prescribed from national } \\
\text { list of essential medicines } \\
\text { (NLEM) 2015 }\end{array}$ & 86.95 & 100 \\
\hline $\begin{array}{l}\text { Number of drugs } \\
\text { prescribed from essential } \\
\text { drug list (EDL) 2019 }\end{array}$ & 69.56 & 100 \\
\hline $\begin{array}{l}\text { Percentage of prescription } \\
\text { with anti-biotic }\end{array}$ & 80 & $20-26.8$ \\
\hline $\begin{array}{l}\text { Percentage of prescriptions } \\
\text { with injection }\end{array}$ & 70 & $13.4-24.1$ \\
\hline
\end{tabular}


Table 5: DDD/patient.

\begin{tabular}{|lllll|}
\hline ATC CODE & Drug name & WHO DDD & DDD & DDD/patient \\
\hline G03AC01 & Norethisterone & $2.5 \mathrm{mg}$ & 108 & 36 \\
\hline B03AA07 & Ferrous sulfate & $0.2 \mathrm{~g}$ & 624 & 23.11 \\
\hline A11EA & B complex & $1 \mathrm{UD}$ & 30 & 15 \\
\hline J01AA02 & Doxycycline & $0.1 \mathrm{~g}$ & 260 & 13.68 \\
\hline A02BC02 & Pantoprazole & $40 \mathrm{mg}$ & 26 & 13 \\
\hline A02BA02 & Ranitidine & $0.3 \mathrm{~g}$ & 138 & 8.11 \\
\hline A11GA01 & Vitamin C (ascorbic acid) & $0.2 \mathrm{~g}$ & 107 & 7.64 \\
\hline P01AB01 & Metronidazole & $2 \mathrm{~g}$ & 75 & 3.94 \\
\hline N02AX02 & Tramadol & $0.3 \mathrm{~g}$ & 9.24 & 3.08 \\
\hline B02AA02 & Tranexamic acid & $2 \mathrm{~g}$ & 36.5 & 3.04 \\
\hline J01DD08 & Cefixime & $0.4 \mathrm{~g}$ & 9 & 3 \\
\hline A10BA02 & Metformin & $2 \mathrm{~g}$ & 8.5 & 2.83 \\
\hline P02CA01 & Mebendazole & $0.2 \mathrm{~g}$ & 70 & 2.8 \\
\hline A10BB01 & Glibenclamide & $10 \mathrm{mg}$ & 5 & 2.5 \\
\hline J01FA01 & Erythromycin & $1 \mathrm{~g}$ & 2 & 2 \\
\hline J01CA04 & Amoxicillin & $1.5 \mathrm{~g}$ & 1.98 & 1.98 \\
\hline C08CA01 & Amlodipine & $5 \mathrm{mg}$ & 7 & 1.75 \\
\hline N02AX02 & Paracetamol & $3 \mathrm{~g}$ & 7.36 & 1.47 \\
\hline M01AG01 & Mefenamic acid & $1 \mathrm{~g}$ & 2.6 & 1.3 \\
\hline H03AA01 & Levothyroxine & $0.15 \mathrm{mg}$ & 5.76 & 1.152 \\
\hline P01AB03 & Ornidazole & $1.5 \mathrm{~g}$ & 2.31 & 1.15 \\
\hline A06AB02 & Bisacodyl & $10 \mathrm{mg}$ & 1 & 1 \\
\hline A12AA04 & Calcium carbonate & $3 \mathrm{~g}$ & 17.5 & 0.64 \\
\hline
\end{tabular}

$* \mathrm{UD}=$ unit dose.

\section{DISCUSSION}

The study was conducted with 30 gynecology patients. The patient was selected upon the fulfillment of inclusion and exclusion criteria. Our study was observational study taken place in tertiary care teaching hospital. To study the utilization of drugs in patients admitted with abnormal uterine bleeding by using DDD/ATC concept.

The study was conducted with 30 AUB patient in the maximum number of patients were in the age group 3645 years $66.6 \%$, where in Balasubramanian et al and Nair et al and Talukdar et al concluded that higher number of gynecology patient were seen between age group of 4050 years. ${ }^{10-12}$

Among 30 patients 7 (23.3\%) were diagnosed AUB and the co-morbidities condition patient with single comorbidities AUB with severe anemia was most diagnosed. Similar result was reported by Suseela et al. ${ }^{13}$ A contradictory result was shown in a study carried out by Bet al and Gupta et al it was found that AUB with fibroid uterus was the most commonly diagnosed. ${ }^{12,14}$

Out of 30 prescription, the majority of the patient were prescribed ferrous sulfate 27 (90\%) in gynecology department. Similar result was reported by Suseela et al. ${ }^{13}$ And the tranexamic acid was most commonly prescribed anti-fibrinolytic agent for AUB patients. similar result was reported by Suseela et al. ${ }^{13}$ A contradictory result was reported by Bhuvanaswari et al, where they found mefenamic acid is most prescribed anti-fibrinolytic agent. ${ }^{15}$

\section{WHO prescribing indicators}

Average number of drugs per prescription was 10.8 this is deviates from the WHO standards (1.6 to 4.8). The minimum number of drugs per prescription was 5 and the maximum number of prescriptions was 22.

Percentage of drug prescribed in generic name, out of 23 drugs $69.56 \%$ of drug were prescribed in generic name, $30.43 \%$ of drug were prescribed in brand name and nearly similar result were found in $60 \%$ Shinde et al and the WHO recommendation of $100 \% .^{16}$

$86.95 \%$ of drug prescribed were national list of essential medicines (NLEM-2015), 69.56\% of drug prescribed were essential drug list (EDL-2019). There is positive outcome to compared with WHO standards. In similar result was found in EDL 69.8\% Athawale et al. ${ }^{17}$

Out of 30 prescription included in this study, anti-biotic were prescribed in $80 \%$ which was greater than that found in the study carried out by Shinde et al, where they found antibiotic were prescribed $6.3 \% .^{16}$

Out of total 30 prescription, injection was prescribed in $70 \%$ of prescription remaining drugs were prescribed by 
oral route which was slightly greater than that found in the study carried out by Athawale et al, where they found injection prescribed by $84.94 \% .{ }^{17}$

A defined daily dose (DDD) is assigned for drugs that already have an ATC code. It is the assumed average maintenance dose per day for a drug used for its main indication in adults and provide a fixed unit of measurement independent of price, currencies, package size and strength enabling comparisons between population groups.

\section{CONCLUSION}

This study has shown the utilization of drugs prescribed in AUB patient. The most commonly prescribed drug was ferrous sulfate and most prescribed antifibrinolytic drug was tranexamic acid for treating AUB. Our study helps to optimize the drug therapy, improve the quality of care and reduce the negative outcome.

\section{ACKNOWLEDGEMENTS}

I would like to thank Rajah Muthiah Medical College and Hospital for allowing to conduct the study and then I would like to thank my dad Govindasamy and mom Amutha and friends.

Funding: No funding sources Conflict of interest: None declared

Ethical approval: Not required

\section{REFERENCES}

1. Matteson KA, Anderson BL, Pinto SB, Lopes V, Schulkin J, Melissa A. Clark Practice patterns and attitudes about treating abnormal uterine bleeding: a national survey of obstetricians and gynecologists. Am J Obstet Gynecol. 2011;205(4):321-8.

2. Sun Y, Wang Y, Mao L, Wen J, Bai W. Prevalence of abnormal uterine bleeding according to new International Federation of Gynecology and Obstetrics classification in Chinese women of reproductive age: a cross-sectional study. Medicine (Baltimore). 2018;97(31):11457.

3. Davis E, Sparzak PB. Abnormal Uterine Bleeding (Dysfunctional Uterine Bleeding): Stat Pearls Publishing Last Update 2 August 2019.

4. WHO International Working Group for Drug Statistics Methodology, WHO Collaborating Centre for Drug Statistics Methodology and WHO Collaborating Centre for Drug Utilization Research and Clinical Pharmacological Services; 2003. Introduction to drug utilization research. World Health Organization. Available at https://apps.who.int/iris/handle/10665/42627.

5. Available at https://www.who.int/medicines /regulation/medicine/safety/toolkit-indicators/en /index1.htmIDDD indicators. Accessed 10 May 2020.
6. Farrukh JB, Towriss K, McKee N. Abnormal uterine bleeding Taking the stress out of controlling the flow. Canadian Family Physician. 2015;61(8):693-7.

7. Available at https://apps.who.int/medicinedocs/en/d/Js2289e/3.1.html WHO prescribing indicators. Accessed 10 May 2020.

8. National List of Essential Medicines 2015 Central Drugs Standard. Available at http://www.cdsco.nic. in/National\%20List\%20of\%20Essential\%20Medicin e-\%20final\%20copy. pdf. Accessed 10 May 2020.

9. WHO Model Lists of Essential Medicines 20162018. Available at http://www.who.int/ medicines/publications/ essential medicines. Accessed 10 May 2020.

10. Ramalingam K, Gigi A, Thomas AS, Mootaparambil AM, Balasubramanian A. Drug utilization pattern and risk factor assessment on abnormal uterine bledding in reproductive aged women in a tertiary care hospital. Int J Res Pharm Sci. 2019;10(4):268790.

11. Nair R, Mallikarjuna M. Clinical profile of patients with abnormal uterine bleeding at a tertiary care hospital. Int J Reprod Contracept Obstet Gynecol. 2015;4(6):1753-7.

12. Talukdar B, Mahela S. Abnormal uterine bleeding in perimenopausal women: Correlation with sonographic findings and histopathological examination of hysterectomy specimens. J Midlife Health. 2016;7(2):73-7.

13. Suseela LT, Parveen S, Archana D, Prasanna SK, Harini N, Pravallika V. A Study on Incidence, Clinical Profile and Prescribing Pattern in Abnormal Uterine Bleeding in a Tertiary Care Teaching Hospital. Int J Res Review. 2019;6(11):548-60.

14. Gupta A, Rathore AM, Manaktala U, Rudingwa P. Evaluation and histopathological correlation of abnormal uterine bleeding in perimenopausal women. Int J Biomed Advance Res. 2013;4(8):509-13.

15. Bhuvanashwari S, Balasubramaniyan V, Bhuvaneswari K. Prescription pattern in dysfunctional uterine bleeding. Int $\mathrm{J}$ Physical Biological Archives. 2013;4(6):1205-7.

16. Shinde RM, Kale AS, Mahadeo P. Sawant Study of drug prescription pattern and adverse drug reaction monitoring in patients with hypertension and diabetes visiting outpatient department in a government tertiary care hospital in Maharashtra. India Int J Basic Clin Pharmacol. 2019;8(6):1430-6.

17. Athawale SS, Kulkarni MD. Drug utilization study in medicine intensive care unit in tertiary care hospital. Int J Basic Clin Pharmacol. 2020;9(1):151-7.

Cite this article as: Govindasamy D, Karunakaran P, Ramesh R, Paramasivamsasanger K, Ponnusamy R. Utilization of drug in patients admitted with abnormal uterine bleeding in a tertiary care teaching hospital. Int J Basic Clin Pharmacol 2020;9:1258-62. 